\title{
EDUCAÇÃO QUILOMBISTA: UMA PROPOSTA DE EDUCAÇÃO AFROCENTRADA NO BRASIL
}

\section{Ricardo Matheus Benedicto*}

Resumo: O presente trabalho tem por objetivo sustentar que somente uma educação centrada na experiência africana e dos afro-brasileiros - definimos este sistema educacional como Quilombista - é capaz de oferecer a formação que os africanos da diáspora no Brasil necessitam, viabilizando de modo adequado as leis 10.639/03 e 11.645/o8 bem como as Diretrizes Curriculares de 2004 para o ensino de História e Cultura Afro-Brasileira e Africana. O desenvolvimento da Educação Quilombista se impõe, pois vivemos em uma sociedade orientada pelos princípios do eurocentrismo e da supremacia branca. Desse modo, as escolas geradas por esta sociedade são incapazes de atender adequadamente tanto as exigências educacionais dos afro-brasileiros quanto às exigências de uma educação intercultural.

Palavras chave: Afrocentricidade; Educação Quilombista; Interculturalidade; Poder, Racismo.

Resumen: El presente trabajo pretende sostener que sólo una educación centrada en la experiencia africana y el afro-brasileños - definimos este sistema educativo como Quilombista - es capaz de ofrecer la formación que los africanos de la Diáspora en Brasil necesitan, habilitando así las leyes 10.639/03 y 11.645/o8 así como las pautas curriculares de 2004 para la enseñanza de la historia y la cultura afro-brasileñas y africanas. El desarrollo de la educación Quilombista se impone porque vivimos en una sociedad guiada por los principios del eurocentrismo y la supremacía blanca. Así, las escuelas generadas por esta sociedad son incapaces de satisfacer adecuadamente tanto las exigencias educativas de los afro-brasileños como las exigencias de una educación intercultural.

Palabras clave: Afrocentricidad; Educación Quilombista; Interculturalidad; Poder, Racismo.

Outro requisito imprescindível é a construção de instituições independentes da comunidade negra para levar a frente o programa nacionalista. Esta é uma necessidade não-teórica, mas enraizada na realidade concreta: a história nos ensina que as sociedades dominantes não entregarão a sua hegemonia, mas tentarão fazer gesticulações enganadoras para criar a ilusão de que o fazem. Não adianta mais o negro continuar a pedir um lugar ou um pedaço das instituições pertencentes à sociedade branca ou arianoide (convencional ou não convencional) e por ela controladas. O branco lhe dará um "lugar", talvez, mas nunca entregará o poder por força da persuasão moral.

Elisa Larkin Nascimento

\section{Introdução}

\footnotetext{
* Professor do Instituto de Humanidades e Letras Malês da Unilab, Coordenador do Curso de Pedagogia e Coordenador do Grupo de Pesquisa em Educação Afrocentrada. E-mail: ricardomb@unilab.edu.br.
}

As reflexões contidas na epígrafe acima foram publicadas em 1981. A despeito disso, e do fato de a própria Elisa Nascimento reconhecer que Abdias do Nascimento, desde 1968, já tinha a compreensão de que o avanço da comunidade afro-brasileira somente se daria quando criássemos nossas próprias instituições, parece que nossa comunidade, de um modo geral, não concorda com este diagnóstico e por consequência com a solução que ela e Abdias apresentam. Em nosso entendimento, este desacordo quanto a forma de conceitualizarmos a realidade racializada em que vivemos pode ser lido como uma divergência quanto à compreensão do que é o racismo, suas origens e o que de fato caracteriza uma sociedade

BENEDICTO, Ricardo Matheus. Educação quilombista: uma proposta de educação afrocentrada no Brasil. Revista Sul-Americana de Filosofia e Educação. Número 31: mai.-out./2019, p. 18-33. DOI: https://doi.org/10.26512/resafe.vi3o.28254 
racista; por consequência, a divergência se estende aos meios pelos quais o racismo deve ser enfrentado e superado.

Diante deste contexto, na primeira seção deste trabalho apresentaremos nossa compreensão sobre o fenômeno do racismo. Na segunda seção, sustentaremos que a adoção da filosofia educacional integracionista ou assimilacionista - definida como aquela que defende a integração dos afrobrasileiros no sistema educacional hegemonizado pelos brancos - para enfrentar o racismo presente na educação brasileira está fadada ao fracasso. Sendo assim, defenderemos que somente uma filosofia educacional independentista ou nacionalista, que sustenta que nós, afro-brasileiros, devemos criar nossas próprias instituições educacionais, definidas por este autor como Educação Quilombista, pode atender satisfatoriamente a demanda por uma educação que valorize a história e cultura afro-brasileira e africana.

\section{O que significa dizer que existe racismo no Brasil?}

Apesar da influência que o mito da democracia racial ainda exerce na sociedade brasileira, parece haver um certo consenso por mais paradoxal que possa parecer quanto à existência do racismo no Brasil. $\mathrm{O}$ que parece não ser consensual são as explicações sobre a origem e o significado deste complexo fenômeno. Dado este desacordo, é fundamental compreender adequadamente as origens, o desenvolvimento e o que caracteriza esta chaga que assola o país, pois sem este entendimento não é possível enfrentá-la e superá-la de modo satisfatório. Para reali- zar esta empreitada apresentaremos a seguir a concepção de racismo que orientará este artigo. Ela está baseada, principalmente, na obra de Carlos Moore Racismo e Sociedade: novas bases epistemológicas para entender o racismo e de Vulindlela Wobogo Cold Wind From the North: The Prehistoric European Origin of Racism Explained by Diop's Two Cradle's Theory.

De acordo com Moore, o "racismo é um fenômeno eminentemente histórico ligado a conflitos reais ocorridos na história dos povos" (MOORE, 2007, p. 38). Estes conflitos, para Moore, estavam ligados à posse dos recursos necessários para manutenção da vida. Os povos leucodérmicos ao vencerem as várias disputas por territórios com os povos melanodérmicos instituíram sistemas racializados para organizar a posse e a distribuição destes recursos. Para Moore, no entanto, este fenômeno histórico não surgiu na modernidade. O etnólogo sustenta que "desde seu início, na antiguidade, o racismo sempre foi uma realidade social e cultural pautada única e exclusivamente no fenótipo, antes de ser um fenômeno político e econômico pautado na biologia" (MOORE, 2007, p. 22). E enfatiza a importância do fenótipo na compreensão do racismo: “o fenótipo é um elemento objetivo, real, que não se presta à negação ou confusão. É ele, não os genes, que configura os fantasmas que nutrem o imaginário social [..]" (MOORE, 2007, p. 22). Moore sustenta que o racismo surgiu na antiguidade porque em suas pesquisas encontrou por exemplo, algumas sentenças do Rig-Veda - escritas há pelo menos um milênio antes de Cristo como as que seguem: "o Indra protegeu seus súditos arianos durante as batalhas, 
subjugou a gente sem leis para o bem de Manu e conquistou a pele negra"; "você Indra, matador de Vrittra, destruidor das cidades, tem dispersado os dasyu gestados por um ventre negro"; "a cor negra é ímpia” (MOORE, 2007, p. 52).

Outro ponto importante a ser destacado é que para o pensador cubano o racismo não é uma ideologia, ou seja, não é produto da mente de um ou mais pensadores. Ele surge historicamente muito provavelmente durante o período Neolítico. Neste período houve sucessivas migrações devido á última glaciação Würm. Para Moore este contexto propiciou o encontro e o conflito violento de populações que até então se desconheciam. Moore afirma, dados estes elementos: "que o racismo não poderia ter surgido num só lugar geográfico e cultural, a partir do qual teria se irradiado para outras sociedades, senão que seria um fenômeno 'plurigêntico'” (MOORE, 2007, p. 246).

A análise que apresentamos até aqui pode ser resumida da seguinte forma:

Em todas as circunstâncias nas quais podemos identificar o surgimento do racismo, encontramos três dinâmicas convergentes de um mesmo processo: a) a fenotipização de diferenças civilizatórias e culturais; b) a simbologização da ordem fenotipizada por meio da transferência do conflito concreto para a esfera do fantasmático (isso implica fenômenos como a demonização das características fenotípicas do vencido em detrimento da exaltação das características do segmento populacional vencedor); c) o estabelecimento de uma ordem social baseada numa hierarquização raciológi- ca, mediante a subordinação política e socioeconômica permanente do mundo populacional conquistado (MOORE, 2007, p. 247).

Moore chama esta ordem social raciológica de pigmentocracia. Para o autor, este sistema é desenvolvido quando o grupo invasor é minoritário e, desse modo, organiza sua dominação sobre uma realidade demográfica que ameaça absorvê-lo (MOORE, 2007, p. 261). Com medo da sua extinção o grupo minoritário, por meio de relações sexuais violentas e organizadas, produz o que o pensador cubano chama de "populações brancas de fusão”. Para Moore, estes brancos mulatos também pretendem manter a distância somática do grupo dominado. Em suas palavras:

A política de miscigenação, por via da cooptação ${ }^{1}$ racial, faz emergir, permanentemente, setores fenotipicamente diferenciados na população. Por força da disseminação de ideologias de superioridade racial, esses "mestiços" serão conduzidos a gravitar em torno do polo social e racialmente dominante. [...]

O racismo destes "brancos mulatos" não é menos violento, e talvez seja até mais agressivo porquanto a diferença fenotípica observável, comparada com o padrão fenotípico que caracteriza o segmento subalternizado se encontra minorado por consequência da miscigenação (MOORE, 2007, p. 260-261).

Moore afirma que neste sistema são as diferenciações da cor da pele, da textura do cabelo, da forma dos lábios e da configuração do nariz que determinam o status

\footnotetext{
${ }^{1}$ Os itálicos são do original.
} 
coletivo e individual das pessoas na sociedade (MOORE, 2007, p. 26o). Assim, o desejo da brancura se origina nestas sociedades porque a camada dominante não é "branca pura". Como aspiram a este ideal, criam a ilusão de que a mestiçagem produzirá um novo tipo de branco que tomará o seu lugar no concerto da civilização ocidental. Com esta análise, Moore nos mostra que carece de fundamento a ideia de que na antiguidade não havia reprodução biológica racialmente seletiva (MOORE, 2007, p. 264). Assim, utilizar políticas eugênicas como estratégia de dominação não é um fenômeno recente na história da humanidade. Esta estratégia pode ser observada, por exemplo, no modelo ibero-americano de relações raciais ${ }^{2}$ :

Na sua obra $O$ Genocídio do Negro Brasileiro, Abdias do Nascimento (1978) talvez tenha sido o primeiro pensador sul americano a ter enquadrado claramente os preceitos da doutrina da miscigenação na América Latina em uma perspectiva de genocídio [...] tomadas em seu conjunto, essas quatro obras apontam para o fato de que a miscigenação - longe de ser mera interrelação individual e respeitosa, ditada pela afeição, como é conveniente afirmar - é uma política consciente de eugenia racial. ${ }^{3}$ (MOORE, 2007, p. 273)

\footnotetext{
${ }^{2}$ A análise de Carlos Moore ficou restrita aos modelos raciais pré-modernos -, ou seja, pré-capitalistas e pré-industriais - visto que estes, no entender do etnólogo, explicam de modo mais adequado a realidade das relações raciais na América "Latina. Ele definiu e estudou quatro modelos a saber: Modelo Indo Ariano, Modelo Árabe-Semita, Modelo IberoÁrabe e Modelo Ibero-Americano.

3 Os itálicos são do original.
}

Após esta breve análise do trabalho de Carlos Moore, passemos à interpretação de Vulindlela Wobogo. Para o pensador o único racismo que existe é o praticado pelos brancos. Em suas palavras: "Temos definido o racismo, que neste estudo é sinônimo de racismo branco [...] como o abuso racialmente motivado baseado no reconhecimento do fenótipo ou ancestralidade praticado por brancos/europeus, suas instituições e seus aliados." (WOBOGO, 2011, p. 23). Diferentemente do etnólogo cubano, Wobogo explicitamente define o racismo como um abuso praticado por brancos. Embora Moore, ao longo de sua obra, apresente apenas exemplos de racismo praticado por povos leucodérmicos, ele evita a conclusão - e a definição - de Wobogo sustentando que o racismo é um fenômeno universal. Isto é curioso, pois Wobogo sustenta que foi a partir de outro trabalho de Carlos Moore ${ }^{4}$ que passou a considerar o racismo como uma característica da cultura europeia.

Wobogo prefere definir racismo como "abuso" ao invés de "opressão" porque este conceito é utilizado em outra filosofia que o pensador não está disposto a endossar (WOBOGO, 2011, p. 23). Este abuso, de acordo com o pensador, é direcionado preferencialmente contra o fenótipo negro. Como nem todas as pessoas com ascendência africana podem ser reconhecidas por seu fenótipo, a definição do autor inclui a expressão "reconhecimento da ancestralidade", visto que estas pessoas - quando são reconhecidas - também são vítimas do abu-

\footnotetext{
${ }^{4} \mathrm{O}$ trabalho a que Wobogo faz referência é Cuba: The Untold Story. Présence Africaine: Cultural Review of the Negro World 24 (English Edition), $\mathrm{n}^{\mathrm{o}} 52,1964$, p. 177-230.
} 
so racista. Wobogo entende as instituições que praticam o racismo como "qualquer entidade [...] fora das prerrogativas dos indivíduos. Isto inclui costumes e ideias" (WOBOGO, 2011, p. 23). Quanto ao termo “aliados", presente na definição, este pretende dar conta do racismo praticado pelo grupo de ascendência cultural mista.

Wobogo também rejeita a tese de que o racismo é um produto da modernidade ou do capitalismo. Em seu trabalho ele apresenta exemplos de práticas racistas ocorridas na Grécia e Roma antiga, na Índia, entre os hebreus e entre os árabes. Para explicar a origem deste complexo fenômeno ele recorre à da Teoria das duas Origens ${ }^{5}$ de Cheikh Anta Diop (1923-1986). Com ela Diop, em sua obra A Unidade Cultural da África Negra: Esferas do Matriarcado e do Patriarcado na Antiguidade Clássica, mostra que a xenofobia é um dos traços culturais dos europeus que foi formado durante o Paleolítico Superior devido ao ambiente inóspito em que viviam. Para Wobogo, concordando com Diop, a vida nômade dos protoeuropeus engendrou a xenofobia e esta após os conflitos ocorridos entre o Berço Meridional ou do Sul e o Berço do Norte evoluiu para o racismo. Wobogo explica a origem do racismo como se segue:

A origem do racismo branco pode ser relacionada a três fatores. [...] O primeiro fator é a condição ambiental responsável pela diferenciação racial do homo sapiens africano para o homo sapiens europeu; isto se

5 O nome Two Cradle's Theory foi dado por Vulindlela Wobogo em seu texto de 1976 Diop's Two Cradle's Theory and Origin of White Racism, Black Books Bulletin vol. 4 e desde então se tornou clássico. completou por volta de 20000 a. C. Xenofobia, o precursor do racismo, pode ter sido embutida na filosofia social das populações que sobreviveram a idade do gelo [...]. A cultura resultante reteve a xenofobia como um elemento estrutural/filosófico fundamental. O segundo componente é o efeito da vida caçado$\mathrm{ra} /$ nomádica em um clima multisazonal impróprio para estabelecer o modo agrário de existência. Estes efeitos ocorreram entre migração inicial para o norte da recentemente diferenciada raça branca e o fim da sua permanência nas estepes eurasianas por volta de 6000 a. C. Os efeitos destas experiências são explicados por argumentos baseados na teoria das duas origens de Diop [...] WOBOGO, 2011, p. 406).

Quanto ao desenvolvimento do racismo o autor escreve:

O desenvolvimento do racismo como um sistema europeu de dominação é possivelmente relacionado causalmente a três fatores. O primeiro foi a reação dos europeus às culturas africanas do berço meridional que eram baseadas na agricultura, como explicado por Josef Bem Jochanan, e em menor grau aquelas da Ásia. O segundo fator foi a redução dos africanos e asiáticos conquistados à condição de escravo nas áreas controlados por europeus de acordo com as teses de Chancellor Williams e Frantz Fanon. O terceiro fator é a reação psicogenética ao percebido status minoritário em relação aos africanos em dado local de acordo com a tese psicogenética de Frances Cress-Welsing. Este caráter minoritário, baseada na tese de Cress, parece soar como motivação para erigir características estrutu- 
rais para facilitar o abuso racial e a dominação. O período para estas interações é de 6000 a. C. até o presente.

Como a história avança da antiguidade à contemporaneidade, a importância da reação psicogenética de Cress, aumenta relativamente a outros fatores devido ao gradual desaparecimento da escravidão aberta e o aumento da consciência dos brancos de seu status minoritário no mundo, particularmente durante nos últimos 500 anos. Esta reação é temperada pela identificação oficial de muitas populações de ascendência mista como brancos (semitas e outros) e as preferências dadas a eles no contexto de maioria africana ou de paridade demográfica (Brasil e outros) (WOBOGO, 2011, p. 407408).

Dada a exposição das teses de Moore e Wobogo, podemos perceber que os autores concordam, a despeito das diferenças existentes em suas definições, que o racismo surgiu na antiguidade, que os conflitos entre povos fenotipicamente diferentes foram importantes na maturação da xenofobia do proto-europeus para o racismo e que este pode ser compreendido como um sistema social estruturado para distribuir privilégios políticos, econômicos e culturais ao grupo racialmente hegemônico. Vale destacar também que os autores concordam que este sistema produz ideologias que, para justificar esta modalidade de dominação, desumanizam o grupo considerado racialmente inferior.

Podemos, agora, voltar à questão que intitula esta seção. Este autor considera que existe racismo no Brasil nos termos aqui definidos. No entanto, penso que a maioria da população brasileira rejeitaria esta caracterização. Isto porque, quando elas dizem que existe racismo no Brasil elas, provavelmente, se referem às manifestações discriminatórias que ocorrem nas relações interpessoais. Segundo este entendimento, que confunde racismo e discriminação racial, a existência de pessoas racistas não implica necessariamente a existência de uma ordem social racista. $\mathrm{O}$ raciocínio é formalmente correto, entretanto, como vimos pela análise acima, é fundado no senso comum. Como dissemos, os brasileiros parecem rejeitar a ideia de que vivemos em um sistema de dominação que - é similar em muitos aspectos - produz efeitos semelhantes ao do apartheid da África do Sul. Se a compreensão dos brasileiros sobre o racismo fosse a apresentada neste texto, certamente os afro-brasileiros, que são a maioria da população, e os brancos antirracistas se rebelariam constantemente contra este sistema que, com base no fenótipo, veda ou limita o acesso à educação, aos serviços públicos, às oportunidade de emprego, aos serviços sociais, ao poder político e ao tratamento igualitário nos tribunais de justiça e das forças incumbidas pela manutenção da paz (MOORE, 2007, p. 284). Não é raro ouvirmos que vivemos em um Estado Democrático de Direito. Por este motivo, no começo da seção, afirmei que o mito da democracia racial ainda é muito influente no país.

Este entendimento do racismo como ato discriminatório praticado apenas por indivíduos estimula a crença ingênua - ou nem tanto - de que o racismo ainda existe por causa de pessoas ignorantes, sem instrução e que, desse modo, tende a desaparecer com o avanço educacional e científico 
no país. Sobre este ponto Carlos Moore sustenta que:

A despeito de uma série de evidências, permanece uma interpretação otimista, amplamente arraigada e estimulada na consciência popular, segundo a qual o racismo seria um fenômeno estático, que recuaria constantemente diante da educação, do crescimento econômico - o chamado desenvolvimento -, da expansão dos conhecimentos científicos e mudanças tecnológicas. [...]

Ao contrário de retroceder, como era de esperar, tendo em conta o enorme salto da Humanidade em matéria de educação e de conhecimentos em geral, o racismo se insere na dinâmica socioeconômica do século XXI com um novo e brutal vigor excludente. [...]

Longe de recuar diante da educação e da ciência, e em vez de ser contido pelo acúmulo crescente de conhecimentos, o racismo adentra-se na ciência e converte-se em modo de educação. ${ }^{6}$ Ele ressurge como um racismo mais "científico", mais "refinado" e, crescentemente, mais "cordial" e "educado". A realidade é que, como assinalou pertinentemente o pensador Aimé Césaire, em Discurso sobre o Colonialismo, o racismo evolui constantemente. Ademais, evolui sempre em uma única direção: o nazismo. Cada vez que o racismo recua, ele o faz somente diante de uma ferrenha oposição. E cada vez que essa oposição enfraquece, ele começa novamente a ganhar novos espaços, continuando a evoluir - da mesma forma que evolui o tempo - conforme seu sentido inicial. $O$ racismo nunca recua de forma permanente (MOORE, 2007, p. 286-289).
Para corroborar a explicação de Moore quanto a ausência de fundamento desta crença e que a solução oriunda dela é equivocada, basta lembrar que Rui Barbosa7 (1849-1923) e José Veríssimo ${ }^{8}$ (1857-1916) defenderam a política nacional de branqueamento, que Fernando de Azevedo9 ${ }^{\text {(1894- }}$ 1974) defendeu e implementou no país um sistema educacional fundamentado na eugenia, que Anísio Teixeira ${ }^{10}$ (1900-1971) considerava as culturas africanas primitivas e que Darcy Ribeiro ${ }^{11}$ (1922-1997) considerava que no Brasil nunca houve barreiras de ordem cultural e linguística reforçando, assim, o mito da democracia racial. Estes pensadores, que ao longo da história do país deram sustentação ao sistema de dominação racial - ainda hoje vigente no país - estão longe de serem pessoas ignorantes e sem instrução. Por fim, parece muita ingenuidade acreditar que um fenômeno que surgiu há

\footnotetext{
7 Ver seu artigo A Convenção Fatal: Dois Pontos de Vista. In: A Imprensa. Rio de Janeiro: Ministério da Educação e Saúde, Vol. XXVI Tomo VII, 1899, p. 94. E seu Discurso pronunciado na sessão cívica de 28 de maio de 1917, no Teatro Municipal. Rio de Janeiro: Fundação Casa de Rui Barbosa, 1999, p. 3536.

${ }^{8}$ Ver, por exemplo, a obra a Educação Nacional Rio de Janeiro: Topbooks; Belo Horizonte: PUC Minas, 2013 e o artigo O País Extraordinário In: Jornal do Comércio, o4 de dezembro de 1899.

9 Ver, por exemplo, sua obra Da educação física: o que ela é, o que tem sido e o que deveria ser. São Paulo: Melhoramentos, 1960.e a obra de Jerry Dávila Diploma de Brancura Política Social e Racial no Brasil 1917-1945. São Paulo: UNESP, 2006.

${ }^{10}$ Ver seu artigo Educação e unidade nacional. In: Educação no Brasil. São Paulo: Companhia Editora Nacional, 1976, p. 326.

"Ver a obra Nossa Escola é uma Calamidade, Rio de Janeiro: Salamandra, 1984, p. 22 e seu artigo A América Latina existe? In: Ensaios Insólitos. Rio de Janeiro: Ludens, 2011.
}

${ }^{6}$ As ênfases são nossas. 
mais de três milênios tendo, portanto, que se ajustar a diversas mudanças sociais, políticas e econômicas ao longo da história vá simplesmente desaparecer devido ao avanço da educação como se os sistemas educacionais oriundos de sociedades racistas não estivessem comprometidos com este sistema social.

Entre aqueles que partilham o nosso entendimento do racismo a divergência ocorre quanto aos meios adequados para enfrentá-lo. Especificamente falando do racismo, que historicamente perpassa o sistema educacional brasileiro, penso que este debate deve levar em consideração o princípio de Molefi Kete Asante: "escolas são reflexos da sociedade que as desenvolve (isto é, uma sociedade dominada pelo supremacismo branco desenvolverá um sistema educacional baseado na supremacia branca)" (ASANTE, 1991, p. 170). Se a sociedade brasileira é orientada pelos princípios do eurocentrismo e da supremacia branca segue-se que as escolas geradas por esta sociedade também são. Diante deste fato temos duas alternativas. Tentar reformar o sistema educacional racista ou criar nossos próprios modelos educacionais. Esta será a discussão da próxima seção.

\section{Educação Quilombista ou Integracionis- ta?}

Os defensores da filosofia educacional integracionista sustentam que é tarefa do Estado promover políticas de combate ao racismo no sistema educacional. Fruto das lutas dos movimentos sociais afrobrasileiros as leis 10.639/o3 e 11.645/o8 bem como as Diretrizes Curriculares Nacionais para a Educação das Relações Étnicorraciais e para o Ensino de História e Cultura AfroBrasileira e Africana de 2004 e as políticas de ação afirmativa na universidade são exemplos de políticas educacionais fundadas nesta concepção filosófica. Tomemos como exemplo as Diretrizes Curriculares Nacionais. Nela podemos ler:

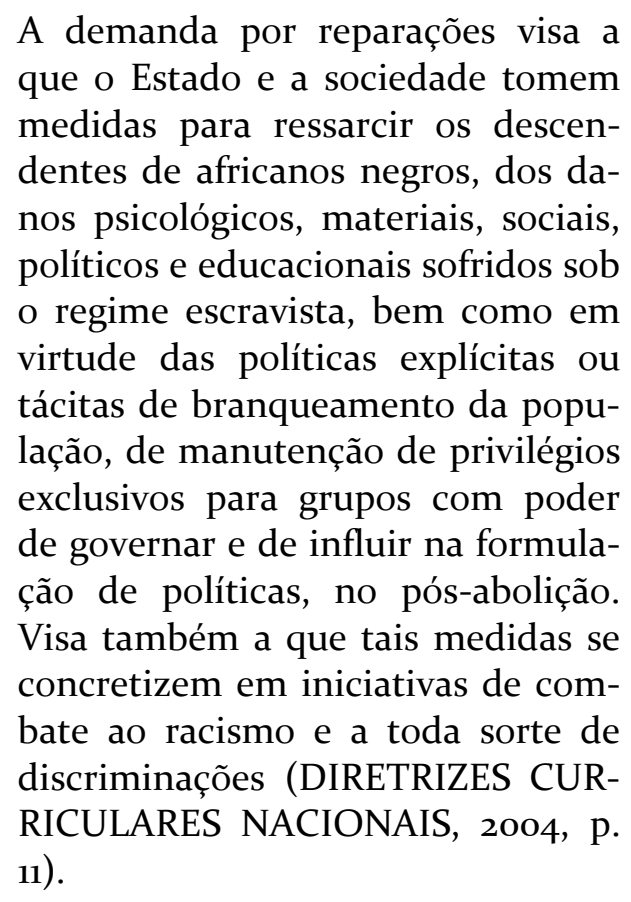

$\mathrm{O}$ excerto acima indica que a orientação teórica deste documento é integracionista. Como asseveramos na introdução deste trabalho, a adoção desta filosofia educacional para a superação do racismo na educação está fadada ao fracasso. Apresentaremos a seguir nossa argumentação.

Para que o Estado combata o racismo presente em seu sistema educacional é preciso que as duas condições a seguir sejam cumpridas: 1) O Estado deve reconhecer que suas instituições de ensino são racistas. 2) Reconhecido o racismo, afro-brasileiros, indígenas e descendentes de europeus devem, em pé de igualdade, decidir qual a me- 
lhor forma de desmantelar as estruturas educacionais monocultutrais em prol de um sistema de educação intercultural. Vejamos se estas condições são cumpridas.

O sistema público de ensino foi implantado no Brasil a partir da década de 30 do século passado. Os pioneiros da educação nova foram responsáveis pelos fundamentos do modelo educacional do país. Entretanto, este modelo foi fundado em bases eugênicas e eurocêntricas. Jerry Dávila na introdução de sua obra Diploma de Brancura escreve: "os chamados pioneiros educacionais do Brasil transformaram as escolas públicas emergentes em espaços em que séculos de suprematismo branco-europeu foram reescritos na linguagem da ciência de mérito e da modernidade" (DÁVILA, 2006, p. 24). E no epílogo de seu trabalho, ao analisar o persistente fascínio brasileiro pela raça sustenta que: "a eugenia perdeu a legitimidade científica após a Segunda Guerra Mundial, mas as instituições, práticas e pressuposições a que ela deu origem - na verdade, seu espírito - sobrevivem" (DÁVILA, 2006, p. 355). Fernando de Azevedo, que foi o primeiro secretário da Sociedade Eugênica de São Paulo fundada por Renato Kehl (1889-1974), nunca reconsiderou suas posições eugênicas. ${ }^{12}$ Críticos deste sistema educacional, como Darcy Ribeiro e Paulo Freire (1921-1997) nunca evidenciaram ou criticaram o caráter eugênico da educação praticada no país. Se o caráter eugênico do sistema nunca foi questionado e os pensadores que sustentaram este modelo ainda

\footnotetext{
${ }^{12}$ Ver o terceiro capítulo de minha tese de doutorado.
}

hoje são reverenciados ${ }^{13}$ fica extremamente fragilizada a defesa da tese de que o Estado reconhece que suas instituições educacionais são racistas.

Quanto à segunda condição também podemos afirmar que não é cumprida. Não é possível indicar um momento preciso na história em que a sociedade brasileira tenha decidido romper com o sistema racista. Esta chance foi perdida no final do século XIX, visto que o projeto "republicano" foi orientado pela política nacional de branqueamento. Como vimos, a sociedade brasileira - a despeito da política de embranquecimento ter como objetivo o extermínio dos afro-brasileiros - nunca se reconheceu racista nos termos definidos neste texto. Durante a maior parte do período republicano sequer admitia sua existência. Desde então, não houve um momento em que os representantes dos afro-brasileiros, indígenas e descendentes de europeus em igualdade de condições se reuniram para apresentar à nação uma proposta para desmantelar as instituições educacionais racistas e construir instituições que respeitem e valorizem as tradições africanas, afro-brasileiras, indígenas e europeias.

Diante do exposto, podemos perceber que a posição integracionista, para fazer sentido, precisa pressupor que o Estado brasileiro não é racista. Pois se fosse, teria

\footnotetext{
${ }^{13}$ Em sua obra História das Ideias Pedagógicas no Brasil, cuja última edição é de 2014, Dermerval Saviani ao analisar a Escola Nova e o pensamento da denominada por ele chama "trindade cardinalícia" não faz qualquer menção ao fato de que tanto a Escola Nova quanto os trabalhos de Fernando de Azevedo, Anísio Teixeira e Lourenço Filho (1897-1970) estão comprometidos com a eugenia e o eurocentrismo.
} 
que reconhecer que nestas condições os afro-brasileiros não têm poder. Isto significa que não temos controle sobre as instituições do Estado. Se não controlamos as instituições educacionais não temos como executar as políticas reparatórias mencionadas no documento. A alternativa que resta aos integracionistas é supor a inexistência do racismo e defender que o que deve ser combatido - com as políticas que defendem - são os efeitos de um sistema que já não existe. Isto pode ser percebido no excerto que utilizamos das Diretrizes Curriculares Nacionais. Se, ao contrário do que dissemos, os integracionistas admitem a existência do racismo devem, então, assumir a posição estranha e contraditória de que o grupo branco hegemônico que controla o Estado não sabe que a educação que defende e promove é racista e eurocêntrica. Pois, se não fosse assim, que sentido poderia haver em tentar convencer um Estado racista a adotar políticas de combate ao racismo?

O educador Asa Hilliard trata deste tópico da seguinte maneira:

\begin{abstract}
Algumas formas de educação multicultural procedem como se a opressão calculada só existisse no passado. Seu preceito parece ser "Agora temos de esquecer e seguir em frente $^{\prime 14}$. Respondendo de forma tópica a ações negativas visíveis como estereótipos e preconceitos, elas perdem de vista as estruturas de dominação em grande parte invisíveis, sobretudo as estruturas educacionais. Não conseguimos perceber o vínculo entre as estruturas educacionais e o plano estratégico com vis-
\end{abstract}

\footnotetext{
${ }^{14}$ As aspas são do original.
}

tas à hegemonia (HILLIARD, 2009, p. 323).

O alerta de Hilliard é importante, pois ao ignorar o tema do poder e hegemonia a agenda multicultural integracionista tende a centrar esforços no estudo de problemas - que, apesar de importantes, tendem a trivializar o debate e a compreensão sobre a hegemonia - como relações raciais, preconceitos, estereótipos, inclusão, valorização da diversidade. Para o educador "precisamos avançar além do trivial e dar o máximo de prioridade e atenção ao problema mais importante: a contenção global das famílias étnicas e a destruição de suas próprias estruturas e processos educacionais altamente eficientes" (HILLIARD, 2009, p. 318).

Por fim, vale destacar que a crítica às deficiências do integracionismo como orientação teórica dos afro-brasileiros não é nova. Elisa L. Nascimento em sua obra PanAfricanismo na América do Sul Emergência de uma Rebelião Negra nos mostrou os limites desta posição. Sua crítica também nos ensinou que as legislações antirracistas brasileiras - ela tratou especificamente da Lei Afonso Arinos - se constituem em verdadeiros passes de magia branca para iludir os afro-brasileiros de que avanços têm sido feitos no combate ao racismo. ${ }^{15}$ Sua análise da decisão da Suprema Corte dos Estados Unidos sobre a constitucionalidade do programa de ação afirmativa do Estado da Califórnia nos serve de alerta para lembrar-nos

\footnotetext{
${ }^{15}$ A lei 10.639/03 está próxima de completar duas décadas. Apesar de ser uma lei federal a União, os Estados e os Municípios a desrespeitam sem maiores consequências.
} 
que como não temos poder político processo similar pode ocorrer no Brasil:

Foi exatamente esse o significado da decisão da Suprema Corte federal no caso Bakke. Bakke, um estudante de medicina anglo-ariano, questionou a constitucionalidade do programa do Estado da Califórnia em função da "ação afirmativa"16, que ordenava a entrada na faculdade de certa quantidade de estudantes negros, porto-riquenhos e chicanos (mexicano-norte americanos), para compensar o legado de séculos de discriminação racial contra eles e para dar-lhes uma chance de penetrar na profissão. O programa tinha por modelo outros projetos semelhantes do governo federal em vários campos. A Suprema Corte decretou a caducidade da lei que criou o programa, sob a alegação de que discriminava o branco. Tudo voltou à estaca zero. O mesmo fenômeno ocorre em todos os setores da sociedade, acompanhando a autocongratulação satisfeita do "establishment" branco liberal, que se orgulha em haver vencido o racismo norteamericano. A democracia racial" chegou também aos Estados Unidos (NASCIMENTO, 1981, p. 49).

Agora que descartamos o integracionismo como alternativa para a superação do racismo na educação brasileira apresentaremos a opção que julgamos adequada. Antes, porém, vamos assumir um princípio que deveria ser básico: a obrigação de educar as crianças e jovens afro-brasileiros, a geração mais jovem, é nossa, da geração mais velha. Devemos ter consciência de que esta responsabilidade não deve ser transfe-

\footnotetext{
${ }^{16}$ As aspas do excerto são do original.
}

rida para ninguém. Muito menos a um Estado comprometido historicamente com práticas genocidas contra a nosso povo. Como afirmou Jacob Carruthers (19302004):

Devido ao sinistro projeto eurocêntrico de educação para nossa juventude negra, devemos considerar como questão de senso comum a educação afrocentrada. (Rejeitarei sem comentar a absurda noção que um currículo universal é a solução.) Vamos agora deixar o caso um pouco mais claro.

A crise endêmica na educação negra é a base do que Bobby Wright chama de "Menticídio". ${ }^{17}$ Menticídio é a fase mais sofisticada da estratégia de guerra dos supremacistas brancos contra a raça negra. Se perdermos esta guerra não haverá mais problemas na educação negra, nem educação negra e nem negros. [...] Se quisermos vencer a guerra contra o supremacismo branco, se quisermos viver, então devemos tirar a educação das mãos de nossos inimigos. Nós devemos construir a verdadeira educação africana sobre uma base revigorada. Somente uma educação afrocentrada oferece esta base. (CARRUTHERS, 1999, p. 260).

Estamos de pleno acordo com Carruthers. Parafraseando sua reflexão: somente uma educação afrocentrada é capaz de solucionar o problema educacional dos afro-brasileiros. Dado este pressuposto, explicitemos o que é a afrocentricidade. Conforme Molefi Kete Asante, formulador do paradigma afrocêntrico, “a afrocentricidade é um tipo de pensamento, prática e perspec-

${ }^{17}$ As aspas são do original. 
tiva que percebe os africanos como sujeitos e agentes de fenômenos atuando sobre a sua própria imagem cultural e de acordo com seus próprios interesses humanos"18 (ASANTE, 2009, pag. 93). Asante sustenta a importância deste paradigma porque "tendo sido os africanos deslocados em termos culturais, psicológicos, econômicos e históricos, é importante que qualquer avaliação de suas condições em qualquer país seja feita com base em uma localização centrada na África e sua diáspora" (ASANTE, 2009, pag. 93).

Asante argumenta que a hegemonia do paradigma eurocêntrico faz com que os africanos do continente e da diáspora se vejam por meio dos olhos do dominador. Por isso os conceitos de agência e localização psicológica, cunhados pelo autor, são fundamentais no paradigma afrocêntrico. De acordo com Asante: "um agente, em nossos termos, é um ser humano capaz de agir de forma independente em função de seus interesses. Já a agência ${ }^{19}$ é a capacidade de dispor dos recursos psicológicos e culturais necessários para o avanço da liberdade humana" (ASANTE, 2009, p. 94). Como afirmamos, o interesse pela localização psicológica também é imprescindível para Asante, pois por meio dela é possível verificar a perspectiva que orienta o trabalho de qualquer pesquisador. Podemos avaliar se uma pessoa está localizada em uma posição central em relação ao mundo africano pelo modo como ela se relaciona com a informação africana. Se ela se refere aos africanos

\footnotetext{
${ }^{18}$ Os itálicos são do original.

${ }^{19}$ Os itálicos são do original.
}

como "outros", percebemos que os vê diferente de si mesma (ASANTE, 2009, p. 96).

Por meio do aparato teórico conceitual afrocêntrico os africanos têm condições de desenvolver uma identidade positiva e assumir o controle - agência - de suas vidas. Como historicamente os africanos independentistas são rotulados maliciosamente de racistas às avessas, Asante faz a seguinte advertência: "deve-se enfatizar que a Afrocentricidade não ${ }^{20}$ é a versão negra do eurocentrismo. $\mathrm{O}$ eurocentrismo é baseado em noções de supremacia branca [...]" (ASANTE, 1991, p. 170). E aponta para a interculturalidade: "diferentemente do eurocentrismo, a afrocentricidade condena a valorização etnocêntrica às custas da degradação das perspectivas dos outros grupos" (ASANTE, 1991, p. 171).

E o que seria uma educação afrocentrada no Brasil? Como já antecipamos defendo o modelo de Educação Quilombista que foi definido em minha tese de doutorado como se segue:

[...] um processo de transmissão dos valores, crenças, costumes e conhecimentos para que os afrobrasileiros possam viver de maneira adequada nesta sociedade garantindo, assim, a continuidade do seu povo e de sua cultura. Esta educação deve ser inspirada na experiência dos quilombos, visto que estas sociedades permitiram aos africanos existirem nesta terra sem renunciarem a sua africanidade, além de serem abertas aos indígenas e brancos excluídos do sistema colonial. Assim como os quilombos se constituíram como espaços de construção

\footnotetext{
${ }^{20}$ Os itálicos são do original.
} 
da identidade afro-brasileira e de resistência à aculturação europeia a educação quilombista, hoje, deve ser concebida como um processo de formação do amefricano do Brasil e de resistência ao historicamente constituído modelo eugênico e eurocêntrico de educação com vistas à construção da sociedade democrática intercultural quilombista (BENEDICTO, 2016, p. 245).

Este conceito foi derivado principalmente do trabalho de Abdias do Nascimento (1914-2011) O Quilombismo. Nascimento é principal pensador afrocentrado no Brasil. Embora não tenha utilizado explicitamente o conceito de afrocentricidade em sua obra podemos perceber que suas reflexões sobre o quilombismo são orientadas pelo paradigma formulado por Molefi Kete Asante. Não é à toa que este último considera Nascimento como um dos seus principais mentores intelectuais ${ }^{21}$. Vejamos de forma detalhada o que caracteriza este modelo educacional.

Nosso conceito de educação é inspirado na definição de Mwalimu Shujaa. Em seu artigo Education and Schooling: You Can Have One Without The Other o educador distingue educação - definida como um processo de transmissão de uma geração para a geração seguinte o conhecimento dos valores, estética, crenças espirituais, e todas as coisas que dão singularidade a uma particular orientação cultural - e escolaridade, definida como processo que tende a perpetuar e manter as existentes relações de poder na sociedade e as estruturas que supor-

\footnotetext{
${ }^{21}$ Esta informação me foi fornecida em meu exame de qualificação pelo professor Renato Noguera da Universidade Federal Rural do Rio de Janeiro.
}

tam estas relações. Shujaa afirma que maioria dos afro-estadunidenses recebem mais escolaridade do que educação. Podemos dizer que fenômeno similar ocorre com os afro-brasileiros. O educador também deixa claro que todo grupo cultural deve providenciar este processo de transmissão ou deixará de existir (SHUJAA, 1998, p. 15).

Como o modelo de educação que defendemos é afrocentrado, ou seja, centrado na experiência africana e afro-brasileira, ele se inspira na experiência dos quilombos, que é um dos nossos principais modelos de organização social e resistência. Nos quilombos as tradições africanas foram preservadas e recriadas. Nesta sociedade os indígenas e os brancos excluídos do sistema colonial eram bem-vindos. Também é importante ressaltar que a experiência africana nas Américas não se restringe à maafa. ${ }^{22}$ Por causa de trabalhos de intelectuais como o professor Ivan Van Sertima (1935-2009) sabemos que os africanos estiveram nas Américas antes de Colombo. ${ }^{23}$ Em sua obra clássica They Came Before Columbus: The African Presence in Ancient America o autor mostrou que os africanos viajaram para a hoje chamada América bem antes que o primeiro europeu chegasse a este continente. Por este motivo utilizamos em nossa definição o conceito de amefricano cunhado pela intelectual amefricana Lélia Gonzales (1935-1994), pois este nos auxilia a compre-

\footnotetext{
${ }^{22}$ Palavra de origem kiswahili que significa holocausto africano, desastre, grande tragédia. Ver Marimba Ani Yurugu: An African-Centered Critique of European Cultural Thought and Behavior. Trenton: Africa World Press, 1994.

${ }^{23}$ Ver também a obra de David Imhotep: The First Americans Were Africans: Documented Evidence, Bloomington, Author House, 2011.
} 
ender a realidade dos africanos nas Américas. ${ }^{24} \mathrm{O}$ sistema educacional quilombista, então, deve contribuir para a formação da identidade dos afro-brasileiros, além de servir como espaço de resistência ao modelo eugênico e eurocêntrico de educação vigente no país.

Como é possível perceber em nossa definição, o Sistema Quilombista é a aberto a interculturalidade. Aliás, concordando e parafraseando Molefi Asante, uma das condições fundamentais para uma autêntica educação multicultural no Brasil é o desenvolvimento da educação afrocêntrica. A superação do modelo monocultural brasileiro somente ocorrerá quando forem devidamente estabelecidas no país sistemas educacionais orientados pela perspectiva cultural afro-brasileira e indígena. $\mathrm{O}$ descaso de mais de uma década para com as leis federais 10.639/o3 e 11.645/o8 corrobora nossa tese.

Por fim, vale destacar que a proposta educacional Quilombista, diferente das políticas educacionais integracionistas, está atrelada a um projeto de sociedade inspirado nas tradições africanas e afro-brasileiras. Ela é derivada - como dissemos - da filosofia política quilombista de Abdias do Nascimento. Para o pensador “o Quilombismo é um movimento político dos negros brasileiros, objetivando a implantação de um Estado Nacional Quilombista, inspirado na República dos Palmares [...] e em outros quilombos que existiram e existem no país" (NASCIMENTO, 1980, p. 275). E ainda, de

${ }^{24}$ Ver o artigo A categoria político-cultural da amefricanidade. In: Tempo Brasileiro. Rio de Janeiro, no 92/93 (jan./jun.), 1988, p. 69-82. acordo com o intelectual: "o Estado Nacional Quilombista tem sua base numa sociedade livre, justa, igualitária e soberana" (NASCIMENTO, 1980, p. 275). Para Nascimento, a educação deve desempenhar um papel crucial neste projeto. Em suas palavras:

A educação e o ensino em todos os graus - elementar, médio e superior - serão completamente gratuitos e abertos sem distinção a todos os membros da sociedade quilombista. A história da África, das culturas, das civilizações e artes africanas terão um lugar eminente nos currículos escolares. Criar uma Universidade Afro-Brasileira é uma necessidade dentro do programa quilombista (NASCIMENTO, 198o, p. 276).

O sistema educacional que derivamos desta proposta política, visa contribuir para a construção do Estado Quilombista que, uma vez consolidado, suplanta o sistema racista vigente. Concordamos com a tese de Abdias do Nascimento de que o Estado brasileiro - já que os amefricanos são a maioria da população - deve ser orientado pela cultura majoritária. Para a viabilização desta nova sociedade, é imperiosa criação de instituições independentes da comunidade afro-brasileira. Entendemos que este é o melhor caminho para desmantelar a pigmentocracia brasileira.

\section{Considerações Finais}

Neste artigo argumentamos favoravelmente à tese de que somente uma Educação Quilombista (Afrocentrada) é capaz atender de modo satisfatório às necessidades educacionais dos afro-brasileiros viabi- 
lizando assim o cumprimento das leis 10.639/03 e 11.645/08. No entanto, sabemos que esta posição não é majoritária na comunidade afro-brasileira.

Diante deste cenário, no último capítulo de minha tese de doutorado fiz um convite aos pensadores afro-brasileiros da educação para aprofundarmos o debate sobre algumas das questões que retomamos neste texto. Se nossa análise é válida segue-se que é urgente a criação de Modelos Educacionais
Quilombistas (Afrocentrados). Assim, não podemos escapar da seguinte questão: que caminhos devemos percorrer para que este modelo educacional se torne realidade? Desse modo, nestas considerações finais, renovo o convite para aprofundarmos o debate sobre estes temas que considero estratégicos para nosso futuro como família étnica.

\section{Referências}

ASANTE, Molefi Kete. The Afrocentric Idea in Education. In: The Journal of Negro Education Vol. 6o, n.2, 1991, p. 170-180.

Afrocentricidade: Notas sobre uma posição disciplinar. In: Elisa L. Nascimento (org.). Afrocentricidade: Uma abordagem epistemológica inovadora. São Paulo: Selo Negro, 2009, p. 93-110.

BENEDICTO, Ricardo M. Afrocentricidade, Educação e Poder: Uma Crítica Afrocêntrica ao Eurocentrismo no Pensamento Educacional Brasileiro. Tese (Doutorado) Faculdade de Educação da Universidade de São Paulo, São Paulo, 2016.

BRASIL. Diretrizes Curriculares Nacionais para a Educação das Relações Étnicorraciais e para o Ensino de História e Cultura Afro-Brasileira e Africana. Brasilia, DF: Ministério da Educação, 2004.

CARRUTHERS, Jacob H. Intellectual Warfare. Chicago: Third World Press, 1999.

DÁVILA, Jerry. Diploma de Brancura: Política Social e Racial no Brasil 1917-1945. São Paulo: UNESP, 2006.

DIOP, Cheikh Anta. A Unidade Cultural da África Negra: Esferas do Matriarcado e do Patriarcado na Antiguidade Clássica. Angola: Edições Mulemba, 2014.

GONZALES, Lélia. A categoria político-cultural da amefricanidade. In: Tempo Brasileiro. Rio de Janeiro, no ${ }^{\circ 2} / 93$ (jan./jun.), 1988, p. 69-82.

HILIARD, Asa. G. O Rabequista e a Festa: Uma Crítica Africana à "Educação Multicultural" nos Estados Unidos. In: Elisa L. Nascimento (org.). Afrocentricidade: Uma abordagem epistemológica inovadora. São Paulo: Selo Negro, 2009, p. 315-329.

MOORE, Carlos. Racismo \& sociedade: novas bases epistemológicas para entender o racismo. Belo Horizonte: Mazza Edições, 2007. 
NASCIMENTO, Abdias. O Quilombismo. Petrópolis: Vozes, 1980.

NASCIMENTO, Elisa L. Pan-africanismo na América do Sul: emergência de uma rebelião negra, São Paulo: Selo Negro, 1981.

NOGUERA, Renato. Afrocentricidade e Educação: os princípios gerais para um currículo afrocentrado. Revista África de Africanidades, Ano 3, n. 11, novembro, 2010. Disponível em: http://www.africaeafricanidades.com.br/documentos/o1112010 02.pdf. Acesso em 05/03/2019.

SERTIMA, Ivan Van. They Came Before Columbus: The African Presence in Ancient America. New York: Random House Trade Paperbacks, 2003.

SHUJAA, MWALIMU (org). Education and Schooling: You Can Have One Without The Other. In: Too Much Schooling Too Little Education: A Paradox of Black Life in White Societies. Trenton: Africa World Press, 1998.

WOBOGO, Vulindlela. Cold Wind From the North: The Prehistoric European Origin of Racism Explained by Diop's Two Cradle's Theory. Charleston: Books on Demand, 2011.

Recebido em: 05/06/2019

Aprovado em: 31/10/2019 